\title{
The Effect of Growth Conditions on Cyanogenesis by Chromobacterium violaceum
}

\author{
By PAULINE A. COLLINS, PAUL B. RODGERS $\dagger$ \\ AND CHRISTOPHER J. KNOWLES* \\ Biological Laboratory, University of Kent, \\ Canterbury, Kent CT2 $7 \mathrm{NJ}$
}

(Received 28 August 1979)

\begin{abstract}
Cyanide production by Chromobacterium violaceum growing on a L-glutamate/minimal salts medium was stimulated by addition of $2 \mathrm{mM}$-glycine and $0.5 \mathrm{mM}-\mathrm{L}$-methionine to the medium. However, when the initial concentration of glycine was $0.6 \mathrm{~mm}$, a lower level of cyanogenesis was obtained than that with glycine-free medium. Cystathionine, DL-methionine sulphoxide, D-methionine and $S$-adenosyl-L-homocysteine were effective substitutes for L-methionine, but a wide range of other compounds including betaine and choline were inactive. Cyanogenesis was stimulated when threonine was used as a replacement for glycine, but serine and a range of analogues of glycine were ineffective. In a minimal salts medium containing glucose as the carbon source, glycine or $\mathrm{NH}_{4} \mathrm{Cl}$ but not methionine could serve as the sole nitrogen source for growth. Growth on glucose plus $\mathrm{NH}_{4} \mathrm{Cl}$ in the presence of glycine and methionine resulted in greater yields of cyanide than growth on a similar medium in the absence of $\mathrm{NH}_{4} \mathrm{Cl}$. In the latter case raising the initial concentration of glycine, to compensate for its utilization as the sole source of nitrogen, had little effect on cyanogenesis. Addition of cyclic AMP to both the $\mathrm{NH}_{4} \mathrm{Cl}$ containing and $\mathrm{NH}_{4} \mathrm{Cl}$-free media caused a decrease in cyanide formation.
\end{abstract}

\section{INTRODUCTION}

Many fungi and a few bacteria are cyanogenic (Knowles, 1976). Cyanide production by Chromobacterium violaceum, a Pseudomonas species and Pseudomonas aeruginosa is stimulated by addition of glycine and L-methionine to the growth medium (Michaels \& Corpe, 1965; Wissing, 1968; Castric, 1977; Rodgers \& Knowles, 1978). In the snow mould fungus glycine stimulates cyanogenesis but L-methionine has little effect (Ward \& Thorn, 1966; Bunch \& Knowles, 1980). In both bacteria and the snow mould basidiomycete cyanide production exhibits many of the typical properties of secondary metabolite synthesis (Castric, 1975; Rodgers \& Knowles, 1978; Bunch \& Knowles, 1980).

In $C$. violaceum and the snow mould fungus the carbon and nitrogen atoms of cyanide originate from the methylene group and the amino group of glycine, respectively, whereas the carboxyl group of the amino acid is lost as $\mathrm{CO}_{2}$ (Michaels et al., 1965; Ward \& Thorn, 1966; Ward et al., 1977). In contrast, in $P$. aeruginosa both the C-1 and C-2 carbon atoms of glycine can be incorporated into cyanide (Castric, 1977). The mechanism by which methionine stimulates bacterial cyanogenesis is not clear, although it is known not to function as a precursor of cyanide (Michaels et al., 1965).

Many cyanogenic micro-organisms are able to assimilate or detoxify cyanide (Knowles,

$\uparrow$ Present address: Department of Biochemistry, University of Liverpool, Liverpool L69 3BX. 
1976). The pathways involved appear to differ in fungi and bacteria. Fungi degrade cyanide to formamide (Fry \& Millar, 1972; Fry \& Evans, 1977) or $\mathrm{CO}_{2}$ (Bunch \& Knowles, 1980) whereas the major product of cyanide degradation by $C$. violaceum is $\beta$-cyanoalanine (P. B. Rodgers, unpublished observations). The enzymes involved in cyanide degradation by $C$. violaceum are induced at a later stage than the enzyme(s) involved in cyanide synthesis (Rodgers \& Knowles, 1978).

Wissing (1975) reported low levels of cyanide production by a cell-free extract of a Pseudomonas species, but extensive efforts to demonstrate cyanogenesis by extracts of C. violaceum have been unsuccessful (P. B. Rodgers \& F. Wissing, and P. A. Collins, A. W. Bunch \& C. J. Knowles, unpublished observations). In an attempt to circumvent this problem we have adopted a different approach to elucidating the mechanism of cyanogenesis by $C$. violaceum. This approach involves studying the effects on cyanide production of variations in growth conditions and the utilization of glycine analogues.

\section{METHODS}

Organism and growth conditions. Chromobacterium violaceum strain NCIB 9131 was grown on minimal salts medium consisting of $\mathrm{M}-9$ salts (Miller, 1972) with $\mathrm{NH}_{4} \mathrm{Cl}$ omitted, plus $1 \mathrm{ml}$ trace metals $^{-1}$ (Bauchop \& Elsden, 1960) with the $\mathrm{Fe}^{2+}$ concentration raised to $30 \mu \mathrm{M}$ to enhance cyanogenesis (Rodgers \& Knowles, 1978). L-Glutamate ( $10 \mathrm{~mm}$ ) was used routinely as a source of carbon and nitrogen. For termination of growth due to ammonium depletion from the medium, $10 \mathrm{~mm}$-glucose and $2.5 \mathrm{~mm}-\mathrm{NH}_{4} \mathrm{Cl}$ were used; for

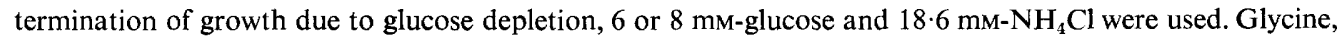
L-methionine, L-tryptophan, cyclic AMP and other additions were used at the concentrations indicated in the text. All amino acids, cyclic AMP and analogues or replacements for glycine and L-methionine were sterilized using a $0.45 \mu \mathrm{m}$ (pore size) membrane filter.

Growth was in $100 \mathrm{ml}$ medium in $250 \mathrm{ml}$ conical flasks, or in $500 \mathrm{ml}$ medium in 21 conical flasks; incubation was at $30^{\circ} \mathrm{C}$ in a gyrotary shaker $\left(250 \mathrm{rev} \cdot \mathrm{min}^{-1}\right)$. For experiments involving extraction of violacein, growth was in $20 \mathrm{ml}$ medium in $100 \mathrm{ml}$ conical flasks. A $2 \%(\mathrm{v} / \mathrm{v})$ inoculum of a 20 to $24 \mathrm{~h}$ stationary phase culture grown on medium containing $10 \mathrm{~mm}$-glutamate was used to inoculate experimental flasks.

Determination of violacein. A $20 \mathrm{ml}$ culture was shaken with 20 or $30 \mathrm{ml}$ ethyl acetate in a separating funnel and the aqueous phase was discarded. Essentially all the violacein was extracted, and a second extraction with ethyl acetate was not necessary (DeMoss \& Evans, 1959, 1960). The concentration of violacein was determined from the absorbance of the ethyl acetate extract at $565 \mathrm{~nm}$ minus the absorbance at $690 \mathrm{~nm}$, using an absorption coefficient of $170001 \mathrm{~mol}^{-1} \mathrm{~cm}^{-1}$ (DeMoss \& Evans, 1960). The pigment was confirmed as violacein by treating it with $100 \mu \mathrm{l}$ concentrated $\mathrm{H}_{2} \mathrm{SO}_{4}$ and measuring the increase in absorbance at $690 \mathrm{~nm}$ (for spectra, see Sneath, 1966).

Determination of residual glycine and methionine in growing cultures. Bacteria $(100 \mathrm{ml})$ were grown in a medium containing $10 \mathrm{mM}$-L-glutamate and $\left[2-{ }^{14} \mathrm{C}\right]$ glycine $[0.6 \mathrm{~mm}$ or $2.0 \mathrm{~mm}, 20 \mu \mathrm{Ci}(740 \mathrm{kBq})]$ plus $0.5 \mathrm{mM}-\mathrm{L}-$ methionine, or $2 \mathrm{mM}$ glycine plus $\mathrm{L}-\left[\right.$ methyl $\left.{ }^{14} \mathrm{C}\right]$ methionine $[5 \mu \mathrm{M}$ or $0.5 \mathrm{mM}, 20 \mu \mathrm{Ci}(740 \mathrm{kBq})]$. Samples $(400 \mu \mathrm{l})$ were removed hourly, starting $9 \mathrm{~h}$ after inoculation, and centrifuged in a Beckman model 152 microfuge for $1 \mathrm{~min}$. The supernatant $(5 \mu \mathrm{l})$ was applied to an Eastman cellulose thin-layer chromatography plate (type 13255) and developed in butanol/acetone/dimethylamine/water (10:10:2:5, by vol.). Glutamate, glycine and methionine ( $1 \mu \mathrm{l}$ of a $10 \mathrm{~mm}$ solution of each) were applied as standards. The amino acids were located by spraying the dried chromatogram with $0.2 \%(\mathrm{w} / \mathrm{v})$ ninhydrin in acetone and warming. The area of the plate corresponding to glycine and L-methionine was removed and counted in $4 \mathrm{ml}$ phase combining system (PCS) scintillation fluid in a scintillation counter. To determine the total number of counts present, $5 \mu 1$ of supernatant was applied to a piece of filter paper, dried and counted as above. Growth and cyanide concentration were measured simultaneously.

Determination of cyanide. Cyanide was assayed by the method of Epstein (1947).

Determination of growth. Growth was followed by measuring the turbidity at $750 \mathrm{~nm}$ using $10 \mathrm{~mm}$ cuvettes.

Materials. Thymine and L-ethionine were obtained from Calbiochem. $N, N$-Diethylglycine was obtained from Eastman Kodak, Rochester, N.Y., U.S.A. Radioactive amino acids were obtained from The Radiochemical Centre, Amersham. All other amino acids and related compounds, vitamin $\mathrm{B}_{12}$, nucleotides and nucleosides were obtained from Sigma. PCS scintillation fluid was obtained from Amersham/Searle, Arlington Heights, Ill., U.S.A. Bis(3-methyl-1-phenylpyrazol-5-one) and 3-methyl-1-phenylpyrazol-5-one 


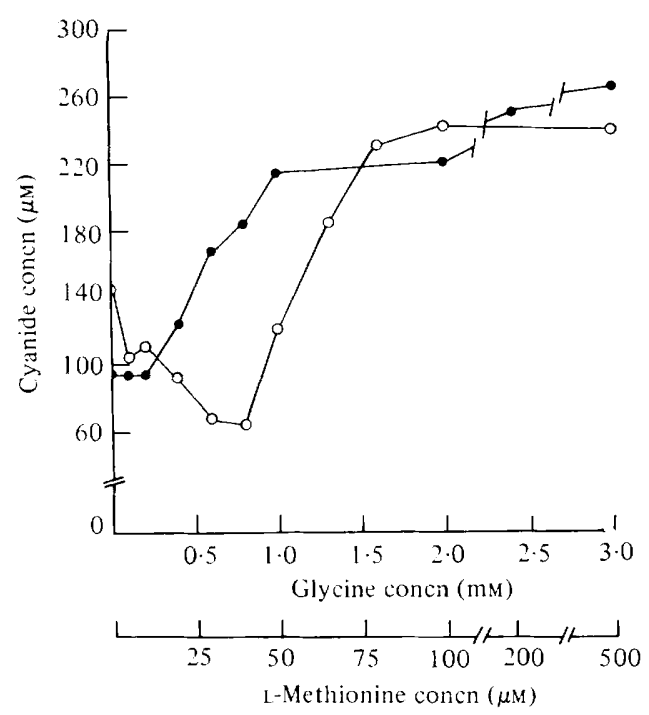

Fig. 1. Effect of glycine and methionine content of the medium on cyanogenesis. Chromobacterium violaceum was grown in a medium containing $10 \mathrm{~mm}$-glutamate in the presence of $0.5 \mathrm{~mm}$-methionine and glycine at various concentrations $(0)$, or in the presence of $2 \mathrm{~mm}$-glycine and methionine at various concentrations $(\boldsymbol{O})$. The cyanide content of the medium was assayed hourly until the maximum concentration was attained ( $14 \mathrm{~h}$ after inoculation).

were obtained from Hopkin \& Williams. All other chemicals were of analytical grade; glass-distilled water was used throughout.

\section{RESULTS}

When $C$. violaceum was grown in a medium containing $10 \mathrm{~mm}$-glutamate, 2 mm-glycine and $0.5 \mathrm{~mm}$-L-methionine, maximum growth was obtained about $10 \mathrm{~h}$ after inoculation and maximum synthesis of cyanide ( 240 to $290 \mu \mathrm{M})$ occurred 12 to $14 \mathrm{~h}$ after inoculation, in good agreement with previous experiments (Rodgers \& Knowles, 1978).

Figure 1 shows the effect of variation of glycine concentration on cyanogenesis during growth on $10 \mathrm{~mm}$-glutamate in the presence of $0.5 \mathrm{~mm}$-L-methionine. As the initial glycine content of the culture was increased up to $0.8 \mathrm{~mm}$ the level of cyanide formation decreased, whereas at higher glycine concentrations there was stimulation of cyanogenesis, up to a maximum at $2 \mathrm{~mm}$-glycine. In contrast, increasing the methionine concentration in the presence of $2 \mathrm{~mm}$-glycine caused only stimulation of cyanide synthesis, up to a maximum at 0.2 to $0.5 \mathrm{~mm}$-methionine. No stimulation of cyanogenesis occurred with initial concentrations of methionine below $10 \mu \mathrm{m}$. Inclusion of glycine and methionine in the medium did not stimulate growth.

Due to the probable utilization of exogenous glycine and methionine during growth, the residual concentrations of glycine and methionine in the medium were measured (i) prior to termination of growth, (ii) at the point of maximum cyanide content of the culture and (iii) during the phase of cyanide degradation $(9,14$ and $18 \mathrm{~h}$ after inoculation, respectively; Table 1). At the maximum stimulatory concentrations of methionine $(0.5 \mathrm{~mm})$ and glycine $(2 \mathrm{~mm})$, about $50 \%$ of the methionine was utilized during growth but there was little further consumption during the period of cyanide degradation (experiment $\mathrm{A}$ ). Nearly half the glycine remained in the medium at the start of the stationary phase, but it continued to be utilized, presumably as the precursor of cyanide, during the period of cyanide synthesis and degradation (experiment B). At an initial methionine concentration 
Table 1. Effect of variation of methionine and glycine content of the medium on cyanogenesis and the amount of the amino acid utilized during growth and the phase of active cyanide production

Chromobacterium violaceum was grown on $10 \mathrm{~mm}$-glutamate plus methionine and glycine at the concentrations indicated. Samples were taken from the cultures at 9, 14 and $18 \mathrm{~h}$ and assayed for growth, cyanide and residual glycine or methionine as described in Methods.

\begin{tabular}{|c|c|c|c|c|c|}
\hline Expt & Additions to medium & $\begin{array}{c}\text { Time after } \\
\text { inoculation } \\
\text { (h) }\end{array}$ & $\begin{array}{l}\text { Culture } \\
\text { turbidity } \\
(750 \mathrm{~nm})\end{array}$ & $\begin{array}{c}\text { Cyanide } \\
\text { concn } \\
(\mu \mathrm{M})\end{array}$ & $\begin{array}{c}\text { Residual } \\
\text { labelled amino } \\
\text { acid } \\
(\% \text { of initial) }\end{array}$ \\
\hline A & $\begin{array}{l}\mathrm{L}-\left[\text { methyl }^{14} \mathrm{C}\right] \mathrm{methionine} \\
(0.5 \mathrm{~mm})+2 \mathrm{~mm} \text {-glycine }\end{array}$ & $\begin{array}{r}9 \\
14 \\
18\end{array}$ & $\begin{array}{l}0.33 \\
0 \cdot 64 \\
0 \cdot 72\end{array}$ & $\begin{array}{l}176 \\
278 \\
156\end{array}$ & $\begin{array}{l}88 \\
50 \\
44\end{array}$ \\
\hline B & $\begin{array}{l}{\left[2-{ }^{14} \mathrm{C}\right] \text { glycine }(2 \mathrm{~mm})} \\
\quad+0.5 \mathrm{~mm}-\text { methionine }\end{array}$ & $\begin{array}{r}9 \\
14 \\
18\end{array}$ & $\begin{array}{l}0 \cdot 33 \\
0 \cdot 64 \\
0 \cdot 76\end{array}$ & $\begin{array}{l}178 \\
286 \\
156\end{array}$ & $\begin{array}{l}47 \\
25 \\
12\end{array}$ \\
\hline $\mathrm{C}$ & $\begin{array}{l}\mathrm{L}-\left[\text { methyl }^{-14} \mathrm{C}\right] \text { methionine } \\
(5 \mu \mathrm{M})+2 \mathrm{mM} \text {-glycine }\end{array}$ & $\begin{array}{r}9 \\
14 \\
18\end{array}$ & $\begin{array}{l}0 \cdot 32 \\
0 \cdot 61 \\
0 \cdot 78\end{array}$ & $\begin{array}{r}121 \\
114 \\
12\end{array}$ & $\begin{array}{l}6 \\
8 \\
8\end{array}$ \\
\hline $\mathrm{D}$ & $\begin{array}{l}{\left[2-{ }^{14} \mathrm{C}\right] \text { glycine }(0.6 \mathrm{~mm})} \\
+0.5 \mathrm{~mm} \text {-methionine }\end{array}$ & $\begin{array}{r}9 \\
14 \\
18\end{array}$ & $\begin{array}{l}0.33 \\
0.82 \\
0.82\end{array}$ & $\begin{array}{r}104 \\
85 \\
31\end{array}$ & $\begin{array}{l}4 \\
5 \\
8\end{array}$ \\
\hline
\end{tabular}

$(5 \mu \mathrm{M})$ that was insufficient to stimulate cyanogenesis, little methionine remained in the culture by the end of the exponential growth phase (experiment C). Similarly, when a low initial concentration of glycine $(0.6 \mathrm{~mm})$ was used, sufficient to partially inhibit cyanogenesis, it was almost completely consumed before the onset of the stationary phase (experiment D).

Table 2 shows the effect of replacing glycine or methionine in glutamate-containing cultures by various analogues, related compounds or metabolites, In the presence of glycine, D-methionine, DL-methionine sulphoxide or metabolites of methionine ( $S$-adenosylL-homocysteine and cystathionine) gave similar levels of cyanogenesis to that caused by L-methionine. Replacement of L-methionine by various analogues (e.g. ethionine), potential methyl-group donors (e.g. betaine), or metabolic end-products of the tetrahydrofolatelinked one-carbon pathway (e.g. purines) resulted in much lower levels of cyanide synthesis. Substitution of threonine for glycine resulted in an increase in cyanogenesis (Table 2), but serine, alanine, cysteine and a range of other compounds were ineffective as replacements for glycine.

Glycine and $\mathrm{NH}_{4} \mathrm{Cl}$, but not methionine, were able to act as nitrogen sources for growth of $C$. violaceum when glucose was the carbon source (Table 3, experiment A). Glycine was unable to act as a carbon source. Tryptophan also served as a nitrogen source for glucose-containing cultures but $\mathrm{KNO}_{3}$ and urea were unable to support growth (results not shown).

Chromobacterium violaceum was grown on a glucose-containing medium such that growth terminated due to either glucose or nitrogen depletion (Table 3, experiment B). In the presence of glycine and methionine, little difference in the level of cyanogenesis was observed. Inclusion of cyclic AMP in the medium caused a partial decrease in cyanide production (Table 3, experiment $\mathrm{C}$ ).

When glycine ( $2 \mathrm{~mm}$ ) was the sole source of utilizable nitrogen, considerably less cyanide was produced than in cultures containing both glycine and ammonia as nitrogen sources (Table 3, experiment C). As less cyanide could have been formed due to glycine depletion from the medium during the former experiment, a higher concentration of glycine $(6 \mathrm{~mm})$ was also used. Again much less cyanide was formed in comparison with cultures in which $\mathrm{NH}_{4} \mathrm{Cl}$ had been added to the medium. In each case cyclic AMP caused a partial decrease in the amount of cyanide produced. 
Table 2. Effect of replacing glycine and methionine by other compounds on the ability of $C$. violaceum growing on $10 \mathrm{~mm}$-glutamate to produce cyanide

Chromobacterium violaceum was grown in a medium containing $10 \mathrm{~mm}$-glutamate with 2 mм-glycine and/or $0.5 \mathrm{~mm}-\mathrm{L}$-methionine. Replacements for glycine were at a concentration of $2 \mathrm{~mm}$, and for methionine at $0.5 \mathrm{~mm}$.

Addition(s) to growth medium containing glycine

$$
\begin{gathered}
\text { Maximum } \\
\text { cyanide } \\
\text { concn }(\%)
\end{gathered}
$$

L-Methionine

$\alpha$-Aminobutyric acid

L-Ethionine

L-Norleucine

Vitamin $\mathbf{B}_{12}$

D-Methionine

Adenine

Adenosine

Guanine

Guanidine

Choline

L-Histidine

Thymine

Thymidine

Betaine

L-Serine

L-Threonine

L-Histidine, adenosine, guanine, thymine

L-Histidine, adenosine, guanidine, thymidine

$S$-Adenosyl-L-homocysteine

DL-Methionine sulphoxide

Cystathionine

None
Addition(s) to growth medium containing

L-methionine

Glycine

L-Serine

L-Threonine

L-Cysteine

Formic acid

$N, N$-Dimethylglycine

$N, N$-Diethylglycine

L-Alanine

Choline

Sarcosine

Formamide

Betaine

Glycinamide

Glyoxylic acid

Methylamine

Glycine ethyl ester

Glycine methyl ester

None
Maximum cyanide conen $(\%)$

$(100)$

36

136

34

38

38

30

23

40

38

41

42

53

13

44

45

60

\section{Table 3. Role of the nitrogen source and cyclic AMP in cyanogenesis} by $C$. violaceum grown on glucose

Chromobacterium violaceum was grown in basal salts medium containing the carbon and nitrogen

\begin{tabular}{|c|c|c|c|c|c|c|c|}
\hline \multirow[b]{2}{*}{ Expt } & \multicolumn{5}{|c|}{ Additions to basal medium } & \multirow[b]{2}{*}{$\begin{array}{c}\text { Maximum } \\
\text { growth } \\
\left(A_{750}\right)\end{array}$} & \multirow[b]{2}{*}{$\begin{array}{l}\text { Maximum } \\
\text { cyanide } \\
\text { concn }\left(\mu_{\mathrm{M}}\right)\end{array}$} \\
\hline & $\begin{array}{l}\text { Glucose } \\
\text { (mM) }\end{array}$ & $\begin{array}{l}\mathrm{NH}_{4} \mathrm{Cl} \\
(\mathrm{mM})\end{array}$ & $\begin{array}{l}\text { Glycine } \\
(\mathrm{mm})\end{array}$ & $\begin{array}{l}\text { Methionine } \\
(\mathrm{mM})\end{array}$ & $\begin{array}{l}\text { Cyclic } \\
\text { AMP } \\
(\mathrm{mM})\end{array}$ & & \\
\hline \multirow[t]{5}{*}{ A } & 6 & $18 \cdot 6$ & 一 & - & - & 0.62 & ND \\
\hline & 6 & - & 5 & - & - & $0 \cdot 89$ & ND \\
\hline & 6 & - & $\cdots$ & 5 & $一$ & $0 \cdot 08$ & ND \\
\hline & 一 & - & 5 & - & $\rightarrow$ & 0.02 & ND \\
\hline & - & $18 \cdot 6$ & 5 & - & - & 0.02 & ND \\
\hline \multirow[t]{4}{*}{$\mathrm{B}$} & 6 & $18 \cdot 6$ & 2 & $0 \cdot 5$ & - & 0.92 & 270 \\
\hline & 10 & $2 \cdot 5$ & $\overline{2}$ & $0 \cdot 5$ & - & $1 \cdot 00$ & 260 \\
\hline & 6 & $18 \cdot 6$ & 一 & -- & - & $0 \cdot 74$ & 46 \\
\hline & 10 & $2 \cdot 5$ & - & -- & 一 & 0.75 & 30 \\
\hline \multirow[t]{8}{*}{$\mathrm{C}$} & 6 & 18.6 & 2 & 0.5 & - & 0.82 & 334 \\
\hline & 6 & $18 \cdot 6$ & 6 & 0.5 & $\ldots$ & 0.83 & 314 \\
\hline & 6 & $18 \cdot 6$ & 2 & 0.5 & 2 & 0.84 & 133 \\
\hline & 6 & $18 \cdot 6$ & 6 & 0.5 & 2 & 0.92 & 226 \\
\hline & 6 & - & 2 & 0.5 & - & 0.88 & 107 \\
\hline & 6 & - & 6 & 0.5 & - & 0.78 & 114 \\
\hline & 6 & - & 2 & 0.5 & 2 & 0.82 & 32 \\
\hline & 6 & - & 6 & $0 \cdot 5$ & 2 & 0.85 & 51 \\
\hline
\end{tabular}
sources indicated. Growth and cyanide production were assayed for up to $18 \mathrm{~h}$ after inoculation; results show the maximum growth and cyanide concentrations obtained. 


\section{Table 4. Effect of inclusion of tryptophan in the growth medium on the synthesis of violacein, and its relationship to cyanogenesis}

Cultures $(20 \mathrm{ml})$ were grown in a medium containing $10 \mathrm{~mm}$-glutamate, or $8 \mathrm{~mm}$-glucose plus $18.6 \mathrm{~mm}-\mathrm{NH}_{4} \mathrm{Cl}$, or $12 \mathrm{~mm}$-succinate plus $18.6 \mathrm{mM}^{-\mathrm{NH}_{4}} \mathrm{Cl}$. Where indicated, $2.5 \mathrm{~mm}$-tryptophan, $2 \mathrm{~mm}$-glycine and $0.5 \mathrm{~mm}$-methionine were added to the medium.

$\begin{array}{llcc}\text { Carbon source } & \begin{array}{c}\text { Addition(s) to } \\ \text { medium }\end{array} & \begin{array}{c}\text { Maximum } \\ \text { cyanide concn } \\ (\mu \mathrm{M})\end{array} & \begin{array}{c}\text { Maximum } \\ \text { violacein concn } \\ (\mu \mathrm{M})\end{array} \\ \text { Glucose } & \text { Trp } & 73 & 22 \cdot 2 \\ & \text { Gly, Met } & 388 & 0 \\ \text { Succinate } & \text { Gly, Met, Trp } & 408 & 23 \cdot 2 \\ & \text { Trp } & 70 & 23 \cdot 0 \\ \text { Glutamate } & \text { Gly, Met } & 302 & 0 \\ & \text { Gly, Met, Trp } & 408 & 24 \cdot 8 \\ & \text { Trp } & 104 & 7 \cdot 0 \\ & \text { Gly, Met } & 294 & 0 \\ & \text { Gly, Met, Trp } & 475 & 9 \cdot 3\end{array}$

In addition to cyanide, $C$. violaceum is able to produce violacein as a secondary metabolite. Violacein is a purple pigment with antibiotic properties formed by dimerization of tryptophan (DeMoss, 1967). It was produced only in cultures containing exogenous tryptophan (Table 4). Glucose and succinate as sources of carbon and energy for growth promoted more violacein synthesis than did glutamate. Stimulation of cyanogenesis by addition of glycine and methionine to the medium had little effect on violacein synthesis in tryptophancontaining cultures. However, in cultures containing succinate or glutamate, but not in those containing glucose, inclusion of tryptophan in the medium stimulated cyanogenesis as well as violacein synthesis when glycine and methionine were also present.

\section{DISCUSSION}

Previous studies have shown that the enzyme system involved in cyanide production from glycine by $C$. violaceum is formed in the late-exponential phase of growth in cultures containing $2 \mathrm{~mm}$-glycine and $0.5 \mathrm{~mm}$-methionine (Rodgers \& Knowles, 1978). In the presence of $0.5 \mathrm{~mm}$-methionine, less cyanide was produced when a low concentration of glycine $(0.6 \mathrm{mM})$ was used than in cultures to which no exogenous glycine had been added (Fig. 1). Contrary to previous suggestions (Michaels \& Corpe, 1965; Rodgers \& Knowles, 1978), this infers that exogenous glycine partially represses the synthesis of the cyanideproducing system that occurs in the late-exponential phase of growth. If this is so, higher concentrations of glycine, such that enough is available to act as the substrate during the cyanide-producing phase, would be necessary for enhanced cyanide formation; this is seen to be the case (Fig. 1). However, confirmation of this tentative hypothesis requires the development of a technique for obtaining cell-free extracts capable of forming cyanide. Interpretation of the effects of exogenous glycine on cyanide production is complicated by the observation that glycine partially represses synthesis of the cyanide-detoxifying enzymes which are induced in the stationary phase of $C$. violaceum cultures (Rodgers \& Knowles, 1978).

The role of methionine in cyanogenesis is not known, except that it is not a substrate for the cyanide-synthesizing system (Michaels et al., 1965). For stimulation of cyanide production to occur methionine must be present during the phase of cyanogenesis, suggesting that it acts as an activator of the cyanide-forming system (Table 1). Methionine is probably not an inducer of the cyanide-forming system as it can be added in the lateexponential phase of growth rather than at the time of inoculation of cultures containing glutamate and glycine without any decrease in cyanogenesis (Rodgers, 1978). 
L-Methionine can be replaced as a stimulator of cyanogenesis by D-methionine, some structurally related analogues, and by metabolites such as cystathionine and $S$-adenosylL-homocysteine (Table 2). This suggests that the stimulatory action may be due to methionine itself or through its metabolic conversion to a stimulatory product. The potential activating role of $S$-adenosyl-L-methionine was not tested as bacteria are impermeable to this compound (Greene \& Radovich, 1975). Michaels \& Corpe (1965) proposed that methionine acts as a methyl-group donor since it could be replaced by betaine, dimethylglycine or choline as a stimulator of cyanogenesis. We were unable to substantiate their findings, and addition of glycine plus choline or betaine to the medium resulted in much less cyanide production than addition of glycine and methionine. However, this conclusion has to be accepted with caution, since these compounds may be unable to enter the bacteria.

Glycine and methionine are biosynthesized by a branched metabolic pathway (Umbarger, 1978). Glycine is formed from serine by the action of serine hydroxymethyltransferase, which also produces a one-carbon unit as $N^{5}, N^{10}$-methylenetetrahydrofolic acid. The latter is partially utilized, after conversion to $N^{5}$-methyltetrahydrofolic acid, to form methionine from homocysteine. Both glycine and one-carbon units are used in the biosynthesis of purines. Therefore, the conversion of glycine to cyanide by $C$. violaceum may be required to limit or permit the continued provision of one-carbon units for synthesis of methionine and purines. The demand for one-carbon units will be decreased in the presence of exogenous methionine, and it is possible that the role of methionine in the cyanide-producing system may be related to the requirement for a rapid removal of glycine. In the presence of exogenous glycine and methionine, the demand for serine for their biosynthesis decreases, especially towards the end of the growth phase, which is the point at which massive cyanogenesis commences. It is interesting that cyanide is later converted mainly to $\beta$-cyanoalanine by a synthase that has serine as its co-substrate (P. B. Rodgers, unpublished observations) and which is inhibited by high concentrations of methionine (Rodgers \& Knowles, 1978). This enzyme, when coupled with the cyanide-producing system, could thereby serve to remove both glycine and serine from the culture.

Several analogues were ineffective as substitutes for glycine for cyanogenesis. This may indicate a complete specificity for glycine, but it should again be remembered that the bacterium could be impermeable to the analogues. Threonine was the only effective replacement for glycine, and actually caused more cyanide synthesis. Presumably threonine was first converted to glycine (Castric, 1977). This could have been due to synthesis of glycine and acetaldehyde by threonine aldolase or serine hydroxymethyltransferase, or of glycine and acetyl coenzyme A by threonine dehydrogenase and glycine-acetyl coenzyme A ligase (Schirch \& Gross, 1968; Newman et al., 1976; Potter et al., 1977). Serine, which is converted to a one-carbon unit as well as glycine by serine hydroxymethyltransferase, was a poor substitute for glycine.

It has been proposed that catabolite regulation (repression and inhibition) is important in the control of synthesis of secondary metabolites (Demain et al., 1979). Glucose, a favourable substrate in the sense that it supports a high growth rate, has often been shown to repress synthesis of antibiotics and other secondary metabolites (Demain et al., 1979). In C. violaceum, glutamate supports a more rapid growth rate than glucose or succinate. Whereas the level of synthesis of cyanide is relatively unaffected by the carbon source for growth, violacein formation is repressed by growth on glutamate. Moreover, regulation of synthesis of these secondary metabolites may be interrelated since the level of cyanide synthesis following growth on succinate or glutamate (but not on glucose) appears to be partially dependent on the level of violacein synthesis.

Termination of growth of $C$. violaceum in glucose-containing cultures caused by depletion of either glucose or ammonia from the medium had little effect on cyanide synthesis. However, the level of cyanogenesis was decreased by addition of cyclic AMP to the 
medium, suggesting that there may be some form of catabolite repression or depression of cyanogenesis.

A valuable clue to the reasons for cyanide formation by $C$. violaceum may be its lower level of synthesis when glycine was the only utilizable source of nitrogen (Table 3). The decrease in cyanogenesis was not due to greater glycine depletion from the medium prior to the onset of the idiophase, since raising the initial glycine concentration did not stimulate cyanide synthesis. Therefore, it could be that cyanogenesis is related to the need to remove excess nitrogen from the culture in a form other than ammonia.

This work was supported by the Science Research Council via grant no. GR/A/11543 to C.J.K. and a research studentship to P.B.R. We thank A. W. Bunch for helpful discussions.

\section{REFERENCES}

Bauchop, T. \& Elsden, S. R. (1960). The growth of micro-organisms in relation to their energy supply. Journal of General Microbiology 23, 457469.

BunCH, A. W. \& Knowles, C. J. (1980). Cyanide production and degradation during growth of the snow mould fungus. Journal of General Microbiology 116, 9-16.

CAstric, P. A. (1975). Hydrogen cyanide, a secondary metabolite of Pseudomonas aeruginosa. Canadian Journal of Microbiology 21, 613-618.

CASTRIC, P.A. (1977). Glycine metabolism by Pseudomonas aeruginosa: hydrogen cyanide biosynthesis. Journal of Bacteriology 130, 826-831.

Demain, A. L., Kennel, Y. M. \& Aharonowitz, Y. (1979). Carbon catabolite regulation of secondary metabolism. Symposia of the Society for General Microbiology 29, 163-185.

DeMoss, R. D. (1967). Violacein. Antibiotics 2, 77-81.

DeMoss, R. D. \& Evans, N. R. (1959). Physiological aspects of violacein biosynthesis in nonproliferating cells. Journal of Bacteriology 78, 583-588.

DeMoss, R. D. \& Evans, N. R. (1960). Incorporation of $\mathrm{C}^{14}$ labelled substrates into violacein. Journal of Bacteriology 79, 729-733.

EPSTEIN, J. (1947). Estimations of microquantities of cyanide. Analytical Chemistry 19, 272-274.

FrY, W. E. \& Evans, P. H. (1977). Association of formamide hydro-lyase with fungal pathogenicity to cyanogenic plants. Phytopathology 67, 10011006.

FrY, W. E. \& MillaR, R. L. (1972). Cyanide degradation by an enzyme from Stemphylium loti. Archives of Biochemistry and Biophysics 151, 468-474.

Greene, R. C. \& Radovich, C. (1975). Role of methionine in the regulation of hydroxymethyltransferase in Escherichia coli. Journal of Bacterio$\log y$ 124, 269-278.

KNowles, C. J. (1976). Microorganisms and cyanide. Bacteriological Reviews 40, 652-680.

Michaels, R. \& CoRpe, W. A. (1965). Cyanide formation by Chromobacterium violaceum. Journal of Bacteriology 89, 106-112.

Michaels, R., Hankes, L. V. \& Corpe, W. A. (1965). Cyanide formation by nonproliferating cells of Chromobacterium violaceum. Archives of Biochemistry and Biophysics 111, 121-125.

Miller, J. H. (1972). Experiments in Molecular Genetics, p. 431. Cold Spring Harbor, New York: Cold Spring Harbor Laboratory.

Newman, E. B., Kapoor, V. \& Potter, R. (1976). Role of L-threonine dehydrogenase in the catabolism of threonine and synthesis of glycine by Escherichia coli. Journal of Bacteriology 126, 12451249.

Potter, R., Kapoor, V. \& Newman, E. B. (1977). Role of threonine dehydrogenase in Escherichia coli. Journal of Bacteriology 132, 385-391.

RodGers, P. B. (1978). Cyanide production and degradation by Chromobacterium violaceum. Ph.D. thesis, University of Kent, Canterbury.

Rodgers, P. B. \& KNowles, C. J. (1978). Cyanide production and degradation during growth of Chromobacterium violaceum. Journal of General Microbiology 108, 261-267.

Schirch, L. \& Gross, T. (1968). Serine transhydroxymethylase. Identification as the threonine and allothreonine aldolases. Journal of Biological Chemistry 243, 5651-5655.

SNEATH, P. H. A. (1966). Identification methods applied to Chromobacterium. In Identification Methods for Microbiologists, part A, pp. 15-20. Edited by B. M. Gibbs \& F. A. Skinner. London $\&$ New York: Academic Press.

UMBARGER, H. E. (1978). Amino acid biosynthesis and its regulation. Annual Review of Biochemistry 47, 533-606.

Ward, E. W. B. \& Thorn, G. D. (1966). Evidence for the formation of $\mathrm{HCN}$ from glycine by a snow mold fungus. Canadian Journal of Botany 44, 95-104.

Ward, E. W. B., Starratt, A. N. \& Robinson, J. R. (1977). Studies of the pathway of HCN formation from glycine in a psychrophilic basidiomycete. Canadian Journal of Botany 55, 20652069.

Wissing, F. (1968). Growth curves and pH-optima for cyanide producing bacteria. Physiologia plantarum 21, 589-593.

WISSING, F. (1975). Cyanide production from glycine by an homogenate from a Pseudomonas species. Journal of Bacteriology 121, 695-699. 